Please do not remove this page

RMIT

UNIVERSITY

\title{
Passive acoustic bubble sizing in sparged systems
}

Manasseh, R; La Fontaine, R; Davy, John; Shepherd, Ian; Zhu, Y

https://researchrepository.rmit.edu.au/esploro/outputs/9921862417901341/filesAndLinks?institution=61RMIT_INST\&index=null

Manasseh, R., La Fontaine, R., Davy, J., Shepherd, I., \& Zhu, Y. (2001). Passive acoustic bubble sizing in sparged systems. Experiments in Fluids, 30(6), 672-682. https://doi.org/10.1007/s003480000245

Document Version: Submitted Version

Published Version: https://doi.org/10.1007/s003480000245

Repository homepage: https://researchrepository.rmit.edu.au

(c) Springer - Verlag 2001

Downloaded On 2023/04/26 20:51:37 +1000

Please do not remove this page 
Thank you for downloading this document from the RMIT Research Repository.

The RMIT Research Repository is an open access database showcasing the research outputs of RMIT University researchers.

RMIT Research Repository: http://researchbank.rmit.edu.au/

\section{Citation:}

Manasseh, R, La Fontaine, R, Davy, J, Shepherd, I and Zhu, Y 2001, 'Passive acoustic bubble sizing in sparged systems', Experiments in Fluids, vol. 30, no. 6, pp. 672-682.

See this record in the RMIT Research Repository at:

https://researchbank.rmit.edu.au/view/rmit:2496

Version: Submitted Version

Copyright Statement: (c) Springer - Verlag 2001

Link to Published Version:

http://dx.doi.org/10.1007/s003480000245

\section{PLEASE DO NOT REMOVE THIS PAGE}




\title{
Passive acoustic bubble sizing in sparged systems
}

\author{
Richard Manasseh, R. Frank LaFontaine, \\ John DAVY, IAN SHEPHERD \& YONG-GANG ZHU \\ CSIRO Thermal \& Fluids Engineering, \\ PO Box 56, Highett, VIC 3190 \\ Melbourne, Australia
}

8 May 2000

\begin{abstract}
Passive acoustic bubble sizing was investigated in both controlled tests and in a stirred sparged tank. Acoustic techniques have promise for industrial systems where other bubble analysis methods are impractical. Acoustic signals were studied for bubbles precisely formed at higher airflow rates. Acoustic pulses varied with bubble production rate as well as bubble size. A technique of windowing pulses is proposed. Two alternative versions of this windowing technique were applied to a stirred sparged tank, giving good agreement. It was shown that, in some cases, it may also be possible to acoustically estimate the spatial distribution of void fraction.
\end{abstract}

\section{Introduction}

Measurement of bubble-size distributions continues to be a problem for many systems. Bubbles of gas (often air) are introduced into many industrial and 
environmental flows to promote a chemical or biological reaction. Aeration (or 'sparging') systems are found in the chemical, minerals processing and pyrometallury industries, and in food, beverage and wastewater processing. In many cases, the bubble-size distribution is a vital control on the rate of gas-liquid mass transfer. In other cases, bubbles of a certain size are a nuisance that must be removed. In the environment, entrapment of bubbles of varying sizes by breaking waves is a mechanism by which oceans absorb 'greenhouse' gases.

For testing industrial aeration equipment, standard void-fraction instruments are available. A sharp-tipped probe registers a binary change in conductivity or refractive index as it pierces a bubble. Clearly, the time-averaged signal from such instruments will represent the local void fraction. However, inferring the bubble-size distribution from void-fraction probes requires many problematic assumptions (Dias, Franca \& Rosa 1997). For example, larger bubbles must not be distorted as they hit the probe; and smaller bubbles must not bounce off the probe.

In the laboratory, bubble sizing has generally relied on high-speed photography, beginning with Knapp \& Hollander (1948). More recently, holography (Lauterborn \& Hentschel 1985) and novel video techniques (Tassin \& Nikitopoulos 1995, Dias, Breit, \& Riethmuller 1997) have been applied. Optical techniques are often unsuitable for a plant environment, where liquids may be opaque or visualization of the flow impossible. Sensitive probes may be damaged in high-temperature or corrosive flows. Even in laboratory models, the presence of particles in a bubbly flow may preclude the use of optical techniques. Significant voidage may also obscure regions of the flow, making optical techniques impractical.

The production of an acoustic signal by bubbles was first detailed by 
Minnaert (1933). Bubbles produce an acoustic signal owing to compression of the gas in the bubble. The compression may be caused by the recoil of the bubble neck on formation, or by deformation of the bubble during its motion, although the precise mechanism of either process is still the subject of research ( e.g. Manasseh et al. (1998)). A full review of bubble acoustics is given by Leighton (1994). It was suggested by Leighton \& Walton (1987) that the sound spectrum produced by bubbles in the environment could be used to calculate the bubble-size spectrum.

Minnaert (1933) showed that under adiabatic conditions, the frequency of the acoustic signal is directly related to the bubble size according to:

$$
f=\sqrt{\left(\frac{3 \gamma P_{\infty}}{(2 \pi)^{2} \rho}\right)} \frac{1}{R_{0}},
$$

where $f$ is the frequency in $\mathrm{Hz}, P_{\infty}$ is the absolute liquid pressure, $\gamma$ is the ratio of specific heats for the gas, $\rho$ is the liquid density and $R_{0}$ is the bubble radius. It may seem surprising that surface tension is not involved, but it can be shown that this is a second-order effect (Longuet-Higgins el al 1991). The bubble only rises a few bubble diameters while it emits the acoustic pulse. Hence $P_{\infty}$ can be considered constant to within a few tenths of a percent. If the liquid is water and is not too deep, $P_{\infty}$ is little changed from atmospheric pressure; for diatomic gases like air, the factor in (1) mutliplying the $1 / R_{0}$ is roughly 3 . Thus, bubbles $1 \mathrm{~mm}$ in radius emit a $3 \mathrm{kHz}$ signal; bubbles $3 \mathrm{~mm}$ in radius emit a $1 \mathrm{kHz}$ signal. These frequencies are generally much higher than mechanical and turbulent noises in a stirred-tank system.

The existence of an acoustic signal leads to several potential experimental techniques. The 'natural' acoustic emissions of a bubbly flow could be used to deduce the bubble-size distribution. This could be called 'passive' 
bubble sizing and is the subject of this paper. It is also possible to insonate a bubbly flow and infer the bubble sizes. This could be called 'active' bubble sizing and requires complex, specialized equipment and sophisticated analyses (Phelps \& Leighton 1998). The passive acoustic signal could also be used as a trigger to enable accurate, high-resolution photography of the bubbles, providing a second check on the bubble size. Work to date on bubble acoustics has mostly investigated the signals produced by small, single bubbles.

As bubbles rise they are distorted by hydrodynamic forces. These shape distortions alter the frequency. Strasberg (1953) has shown how the frequency may be corrected for prolate and oblate spheroidal bubbles. Furthermore, the shape distortions themselves induce acoustic oscillations by nonlinear parametric resonances (Longuet-Higgins 1989). As the airflow nate increases, the bubbling rate increases. The bubbling rate could be considered 'high' once bubbles begin to collide. As the bubbling rate increases, bubbles also become larger and more distorted and begin to affect each other. Under these conditions the relationship (1) will break down and a small-amplitude correction to the basic frequency will no longer be possible.

Several studies have already been made of acoustic spectra in bubbly flows. Pandit et al. (1992) took acoustic data from a turbulent jet containing bubbles. They related the sound-pressure power spectrum directly to the bubble-size distribution. The mean bubble size compared reasonably with photographic estimates. However, in estimating the bubble-size distributions, they relied on the assumption of uniform turbulence in the flow exciting the bubble acoustic emissions. Their bubbles were in the range 0.1 to $1 \mathrm{~mm}$. It was implied by Pandit et al. (1992) that they used a windowing technique, as in the present paper.

Hsi et al. (1985) studied sound spectra in a stirred tank. They focused 
on lower frequencies (below $1 \mathrm{kHz}$ ). They associated this low-frequency sound with the formation of air cavities behind the impeller blades, the flooding of the rotor with air and with large (tens of $\mathrm{mm}$ ) bubbles. Boyd \& Varley (1998) measured a broader spectrum at a point in a stirred tank, and obtained a fair comparison between acoustically and photographically measured bubble sizes. Nevertheless, they noted that further work is required on the causes of bubble sound in this system, before the technique can be universally applied.

In particular, more fundamental work is required on bubble production under continuous sparging conditions. The bubble signals when bubbles are produced continuously appear different to those when the bubbles vibrate in isolation. In the first part of this paper, the signals of bubbles continously produced from a nozzle are studied. In the second part, the findings of the first part are applied to the case of bubbles streaming off a ventilated cavity in a stirred tank.

\section{Fundamental studies}

\subsection{Experimental method}

Bubble-acoustic calibrations on a single stream of continuously sparged bubbles were detailed elsewhere (Manasseh 1997) and only pertinent results are quoted here, together with additional optical data.

Bubbles were produced from vertical-axis nozzles with internal diameters of $0.3,0.5,1.0,2.0$ and $4.0 \mathrm{~mm}$, machined to maintain their internal edges as sharp as possible. This ensured a known contact radius for the forming bubble. The bubbles were produced in pressure-controlled mode, with the exception of the bubbles from the smallest nozzle, which were produced in volume-controlled mode. Explanations of these bubble-production 
modes are given in Chhabra (1993). Bubbles were produced at a depth of $0.238 \pm 0.0005 \mathrm{~m}$ in a box $23 \mathrm{~cm}$ square. A schematic of the equipment set-up is shown in figure 1.

\subsection{Results}

A typical acoustic pulse is shown is figure 2. It was measured using an underwater hydrophone (Bruel \& Kjaer type 8103) near the bubble release point. Tests determined that the presence of the hydrophone did not alter the bubble dynamics or acoustic signal. The bubbling rate was $12 \mathrm{~Hz}$ and the acoustic frequency about $980 \mathrm{~Hz}$. The corresponding spectrum, averaged over 30 bubbles, shows a clear peak at the bubble frequency (figure 3 ). The relevant part of the spectrum (below $2500 \mathrm{~Hz}$ ) for a single bubble is virtually identical. After passing through filters (pass band $600 \mathrm{~Hz}$ to $3 \mathrm{kHz}$ ) and a variable-delay trigger, the acoustic pulse was used to fire a strobe that enabled high-resolution photographs to be taken using a $35 \mathrm{~mm}$ camera (figure 4). Such photographs, which are accurately related to the phase of the acoustic pulse, were used to calibrate the frequency-derived bubble sizes.

To be compared precisely, the frequency measurement must be made at the same time as the optical measurement. This is because the frequency alters with time owing to the nonlinear factors mentioned in $\$ 1$ above. Generally, the frequency reduces with time. Hence, the frequency of the peak in a spectrum of the entire acoustic pulse, such as figure 3 , will be lower than the frequency for the first few periods of acoustic oscillation. As a result, the radius of a bubble assumed to be spherical and calculated using the spectral peak will be an over estimate of the bubble radius just after release. This effect can be seen by comparing figures 5 and 6 . In figure 5 the frequency of the spectral peak is used to calculate the bubble radius via (1). In figure 6 
the 'frequency' used to calculate the bubble radius is in fact the reciprocal of the period of the first acoustic oscillation. For all but the highest airflow rates measured, the bubble production and acoustic oscillation are so regular that this first period can be measured with an error less than $1 \%$. It can be seen that the smaller bubbles are closest to ideal; for these, nonlinear errors due to distortions are minimal.

The photographic measurements have random errors of up to $4 \%$ for smaller bubbles. Optical measurements are also subject to three systematic errors of interpretation. Firstly, it is never certain precisely where the bubble rim is. Secondly, systematic errors for the smaller nozzles (0.3 and $0.5 \mathrm{~mm}$ ) may be up to $10 \%$, owing to the use of the image of the nozzle tip as the datum scaling dimension in the photographs. It is, of course, the outer diameter of the tip that appears in the image, not the precisely machined inner diameter. The outer diameter of the nozzle tip was measured using a graticule under a microscope but is still subject to an error of about $10 \%$. Thirdly, although the bubble is close to spherical at the instant the photograph was taken, there is still an eccentricity. Major and minor axes of the bubble were measured and the photographic radii $R_{p}$ were calculated as an equivalent spherical radius using:

$$
R_{p}=e^{1 / 3} d_{\text {minor }} / 2,
$$

where $e=d_{\text {major }} / d_{\text {minor }}$ is the eccentricity and $d_{\text {major }}$ and $d_{\text {minor }}$ are the measured major and minor axis lengths. The eccentricity is at most $10 \%$ so this correction accounts for less than $3 \%$.

Thus, optical measurements should not be regarded as the 'true' or 'datum' bubble size; in effect, figure 6 is a comparison of two techniques for measuring bubble size, one optical and one acoustic. As a further check, bubble-sizing software (Zhu et al. 1999) was run on digitized bubble images 
and compared with the acoustic measurements. Figure 7 shows that the software and acoustic data agree reasonably well.

The bubble first-period 'frequency' was used to calculate the bubble volume using (1), which together with the bubbling rate can be used to reconstruct the airflow rate through the nozzle. Comparing this with the known flow rate obtained from a calibration gives a useful check of the accuracy of the acoustic technique. This is shown in figure 8.

The agreement on airflow rate appears better than that on bubble radius alone. This is because the airflow rate is the product of bubble volume and bubbling rate. As the airflow rate increases, the bubbling rate increases much more than bubble volume, hence errors on bubble volume become proportionately smaller. As before, the volume is calculated as $4 / 3 \pi r^{3} e$, where $e$ is the eccentricity and $r$ is the minor-axis radius, using estimates of the bubble eccentricity gained from photographic work.

The agreement is good and linear up to a limit which corresponds to the beginning of bubble pairing. Here, the bubble just formed collides with the bubble immediately above (Manasseh 1996). Under some circumstances the bubbles can coalesce, however in this experiment surface tension is sufficiently low to prevent coalescence.

The implication of this work is that for estimates of bubble size, rather than taking overall spectra, individual bubble pulses should be stored and analysed separately. In particular, the earliest cycles of the bubble pulse will yield the most accurate data. 


\section{Tests on a stirred, sparged tank}

\subsection{Equipment, tests and procedure}

Tests of the bubble-acoustic technique were performed on a model of an actual tank used in industry. (It modelled a tank from the Becher process used in the production of titanium dioxide.) Most aeration tanks used in industry have a similar schematic form: a cylindrical tank, stirred by an impeller on the centreline and close to the bottom, and fitted with four vertical baffles to prevent swirling of the bulk of the flow. The tank held 20 litres of tap water, and its diameter was $290 \mathrm{~mm}$. It was made of clear acrylic and was surrounded by a clear water-filled box, thus enabling some visualization of the flow. The speed of the impeller, a Rushton turbine of diameter $D=131 \mathrm{~mm}$, was held at $250 \mathrm{rpm}$. The Rushton turbine is basically a disc with a number of vertical blades fixed normal to it. Air is sparged in below the turbine disc and hence gets distributed by the turbine's action. The principle of the Rushton turbine is the formation of low-pressure regions in the trailing vortices behind each blade. These low-pressure regions attract air into them and form cavities that shed continuous streams of bubbles.

To facilitate measurements at many points in the tank, the probe pivoted about a point movable vertically, while the tank was rotatable through $90^{\circ}$ about its axis. Probe and tank motion were controlled by a computer, as was data recording.

An airflow rate of $Q=1.6$ litre $s^{-1}$ was used. The fluid height was $267 \mathrm{~mm}$. For these conditions, the bubbles form structures known as 'vortex cavities' behind each blade of the Rushton turbine (Smith \& Warmoeskerken 1985).

The work reported in the previous section indicated that only the ear- 
liest stages of each acoustic pulse would yield accurate information on the bubble size. Therefore, the following 'windowing' procedure was adopted:

1. The signal was observed with various trigger settings and at various probe locations. By trial and error, a trigger level was established manually, such that only pulses corresponding to clear bubble signals were captured. For most of the experiments reported here, this trigger level corresponded to a sound pressure of $186.2 \mathrm{~Pa}$ at the hydrophone location.

2. This trigger level was then set, together with a capture time of $15 \mathrm{~ms}$, on the digital oscilloscope, which was controlled by the PC. This capture time was enough to obtain several cycles of acoustic oscillation after the initial sharp rise of the pulse, but no more. Because the actual acquisition was done by the oscilloscope, then transferred over a serial line to the $\mathrm{PC}$, the minimum time $t_{\text {store }}$ required to store one pulse was about $1.97 \mathrm{~s}$, much longer than the $15 \mathrm{~ms}$ capture time.

3. The system was left to capture $n=100$ pulses. These were stored individually, together with data on the time it took to capture each pulse.

A similar windowing technique was used by Pandit et al (1992). Although they did not explicitly state why, it was probably the most practical way of analysing the data, just as with the present data.

As a test, a spectrum was obtained when the data was analysed continuously, with no reckoning if a bubble pulse was present or not. The intention was to compare this spectrum with that obtained with the triggering method. 
The signal was low-pass filtered at the charge amplifier with a $10 \mathrm{kHz}$ cutoff and then high-pass filtered with a $500 \mathrm{~Hz}$ cut-off. To ensure exactly the same data were analysed by the two techniques, it was recorded on Digital Audio Tape (DAT) by a Sony TCD D7 recorder which has a digitising rate of $44 \mathrm{kHz}$, and this data was played back through the two techniques. Figure 9 shows the acoustic spectrum at one point in the tank, when the data were analysed continuously. A digital oscilloscope (HP $35670 \mathrm{~A}$ ) was set to 1600 lines resolution (4096 points) and a span of $12.8 \mathrm{kHz}$, which corresponds to a sample length of $125 \mathrm{~ms}$. Hence 2224 averaged samples of this data covers $278 \mathrm{~s}$. These 2224 samples took $280 \mathrm{~s}$; thus the data coverage was effectively continuous. Only the part of the spectrum below $3 \mathrm{kHz}$ is shown in figure 9 since there is no significant signal power above $3 \mathrm{kHz}$. Checks for aliasing were performed by resampling the data at up to $104 \mathrm{kHz}$. The mean of the 2224 averaged spectra is the central curve in figure 9; the two bounding curves represent $95 \%$ statistical confidence limits. The sharp drop-off in signal power at $500 \mathrm{~Hz}$ is due to the high-pass filtering applied to the signal. The signal power falls quickly until about $2 \mathrm{kHz}$ and it tails off gradually above $2.5 \mathrm{kHz}$.

The spectrum obtained by the windowing technique using the same (HP 35670A) digital oscilloscope is shown in figure 10. Here a trigger was set with a level corresponding to a sound pressure of $186.2 \mathrm{~Pa}$ at the hydrophone location (roughly $40 \%$ of the typical peak signal). Data were captured for $15.6 \mathrm{~ms}$ and zero-padded out to $125 \mathrm{~ms}$. The spectra were taken at the same resolution (1600 lines) as for the continuous analysis, giving the same frequency span of $12.8 \mathrm{kHz}$. The spectra from 100 windowed samples were averaged. Figure 10 thus represents considerably less data than figure 9 (100/2224 is less than 5\%). The $95 \%$ confidence limits bounding the averaged 
curve are therefore broader. It is clear that the windowing technique results in a much peakier spectrum. Individual sub-peaks that may correspond to features of the bubble-size distribution are apparent. This information has been lost from the continuous spectrum.

The windowing technique focuses the analysis on the first few cycles after a peak in signal intensity. Since the loudest sounds in this system are made by bubbles, the windowing technique focuses the analysis on the first few cycles of bubble-acoustic oscillation, which from $\$ 2.2$ gives the best estimate of bubble size. Clearly, however, a window selected by a signal-level trigger biases the analysis towards bubbles that are large and very close to the hydrophone, because the sound pressure falls off both with distance and bubble size. It also biases the analysis towards bubbles excited to a higher amplitude; this will be discussed in $§ 3.3$.

The same trigger level was used both near to and far away from the turbine. Close to the turbine-blade tips, bubbles are produced continually from the cavities behind the blades and loud bubble pulses occur virtually continuously. The trigger level setting was such that at these locations, the time spent waiting for a suitably loud bubble pulse was virtually zero. However, in regions of the tank far from the bubble-formation zones, bubble pulses loud enough to be captured were rare. In some locations the system waited half an hour to obtain 100 pulses, while close to the turbine the time to obtain 100 pulses tended to the minimum of $1.97 \mathrm{~s}$.

Data recording commenced with the probe pivoted to the setting closest to the vertical and the probe at the lowest sampling point.

The probe was then progressively raised through the higher levels, waiting at each until all the required data had been obtained. After the probe recorded the upper-most position, the tank was rotated $5^{\circ}$ and the above 
sequence repeated.

\subsection{Results - spatial distribution of bubble sizes}

Figures 11, 12 and 13 show results of the acoustic technique in the model stirred sparged tank. The plane shown cuts a diameter through the tank intersecting a pair of baffles. The probe-traversing system described in $§ 3.1$ resulted in data on a grid of 14 points across the diameter and 13 points in the vertical; and there were 7 such planes cutting progressively smaller chords of the tank, so the plane shown is the one with the most data. The data have been bilinearly interpolated within the pixel corresponding to each measurement location to give a continuous effect, but no additional data smoothing or spatial filtering has been performed. The significant assymetry is due to the presence of baffles in the tank coupled with the swirling nature of the flow. The impeller was turning clockwise, viewed from above.

Figure 11 shows the distribution of average bubble sizes, obtained through a windowed spectrum, calculated in the same way as that of figure 10 . In fact, figure 10 is the data from the point at the bottom row of the tank and just to the left to the white 'danger zone' surrounding the impeller in figure 11. Recall that figure 10 is the average of 100 windowed spectra. To get an average bubble size at each point, the mean frequency of spectra such as that of figure 10, were calculated, and the bubble size calculated from this frequency simply by using (1). It would also be possible to obtain a distribution of bubble size at each point, following a procedure such as that described by Pandit et al. (1992), but the aim here is simply to see how the bubble size varies with location in the tank.

Figure 12 shows the distribution of average bubble sizes calculated from the first period alone, as described in $§ 2.2$. The general pattern is very similar; 
only, as expected from the results of $\$ 2.2$, the bubble sizes are somewhat smaller. The similarity of the pattern is evidence that the bubble-acoustic technique is quite robust: quite different analysis techniques will give similar results.

In both figures 11 and 12, the zone of largest bubbles is found above the impeller and a 'chimney' of large bubbles rises up the tank centre to the surface. This can be explained, given an understanding of the typical flow in such tanks. The impeller creates a toroidal vortex that sends small, newly-formed bubbles radially outwards. On reaching the wall, some bubbles are recirculated inwards and downwards. Because they are moving against their buoyancy, these bubbles are the slowest moving, and thus have the greatest opportunity to coalesce (Bhaga \& Weber 1981). The result is a zone of large bubbles above the impleller. These large bubbles get sucked into the impeller blades, forming the two 'legs' in the pattern (really a cone in three dimensions).

\subsection{Estimate of void-fraction distribution}

While the spatial distribution of bubble size is important, it is equally important for mass-transfer applications to know the distribution of void fraction or the population density of bubbles. In general, the acoustic technique cannot directly provide this information; however, it may be possible to estimate the void fraction, employing some assumptions based on the use of the windowing technique.

It can be shown that instantaneous sound pressure $p(t)$ produced by a single bubble is given by

$$
p(t)^{2}=\frac{1}{f^{2}} \frac{3 \gamma P_{\infty}^{3} /\left(4 \pi^{2} \rho\right)}{(\gamma(\gamma-1) r)^{2}} X(t)^{2},
$$


where the bubble is undergoing adiabatic compressions, $f$ is the bubble's natural frequency given by (1), $r$ is the distance from the bubble and the time-dependent factor $X(t)$ is given by

$$
X(t)=\left(\frac{4}{3}-\gamma\right)\left(\frac{R_{0}}{R(t)}\right)^{3 \gamma-1}+\frac{1}{3}\left(\frac{R_{0}}{R(t)}\right)^{2}
$$

(Pandit et al. 1992), where $R(t)$ is the intantaneous value of the bubble's radius as it oscillates about its equilibrium radius $R_{0}$.

Unfortunately, we do not know what the function $R_{0} / R(t)$ is in general; this requires knowledge of the phenomena distorting the bubble, which may well be different for different sized bubbles. In a generally turbulent flow where energy is present at a wide range of length scales, it may be valid to assume that $R_{0} / R(t)$ is the same for all bubble sizes; this was assumed by Pandit et al. (1992) for their turbulent jet. It is unlikely we can make the same assumption in all regions of the more complex stirred tank. Nevertheless, near the impeller tips, the sounds recorded are those of bubbles being formed. Bubble formation causes distortions to the bubble shape that are self-similar for bubbles 2-8 mm in diameter (Manasseh 1997), so there may be some validity for the assumption of self-similar $R_{0} / R(t)$ in this zone.

In a system where $R_{0} / R(t)$ is self-similar, the peak value of $X(t)$ would be independent of bubble size, so the peak value $\hat{p}$ of $p(t)$ would be given from (3) by

$$
\hat{p}^{2}=k R_{0}^{2} / r^{2},
$$

where $k$ is a constant, since $1 / f^{2} \propto R_{0}^{2}$ from (1). When individual bubble pulses are captured with the use of a fixed trigger level (hence a fixed $\hat{p}$, say $p_{\text {trig }}$ ), a bubble of given size $R_{0}$ will be detected by the system provided its 
centre is within a critical radius $r_{c}$ of the hydrophone, given by:

$$
r_{c}=\frac{\sqrt{k}}{p_{\text {trig }}} R_{0}
$$

In other words, if we accept the assumption of self-similar bubble distortions ('Assumption 1'), a bubble twice as big will be detected twice as far away for the same trigger level.

Next, assume that the windowing period is sufficiently brief that overlap events do not occur ('Assumption 2'). In other words, the actual bubble detected is the only bubble within the critical radius during the windowing period. The probability that two bubbles coexist within the critical radius during the windowing period is considered negligible.

Therefore, the instantaneous void fraction $\alpha$ (during the windowing period) is given by the ratio of the bubble volume to the volume within the critical radius (plus a bubble radius),

$$
\alpha=\frac{R_{0}^{3}}{\left(r_{c}+R_{0}\right)^{3}},
$$

neglecting the volume occupied by the hydrophone itself. Since from (6) $r_{c} \propto R_{0}$, the conclusion is that the instantaneous void fraction $\alpha$ is a constant. Rather than guessing the constant $k$, which depends on the unknown $R_{0} / R(t)$, it was determined from the experiments of $\$ 2,2$ for bubbles of the size range found in the stirred tank.

For the present paper the intention is not to accurately quantify $\alpha$, but to use the fact that $\alpha$ may be considered constant to determine the relative spatial distribution of void fraction.

It should be noted in passing that for some experiments, the trigger level was set sufficiently high so that $\alpha=0.13$ or roughly $1 / 8$; thus, $r_{c} \simeq R_{0}$ 
and the bubble had to be virtually touching the hydrophone for it to be detected. In this case, any error in assuming the bubble detected is the only bubble within the critical radius is virtually eliminated. (Although to be precise when such 'close-range' measurements are being made, the volume of the hydrophone itself should be included.) Hence, by estimating the 'instantaneous' void fraction in this way, it is possible to make the hydrophone function virtually as a electrical or optical void-fraction probe - without having to pierce the bubble. Of course, because the volume of the hydrophone (a cylinder about $25 \mathrm{~mm}$ long and $9.5 \mathrm{~mm}$ in diameter) is much greater than the volume of the tip of a typical void-fraction probe, the spatial resolution is much poorer, but is still good for testing most industrial systems. For most of the present experiments, $\alpha$ was 0.39 .

To estimate the average void fraction, it remains to calculate the fraction of the total time that bubbles are present within the critical radius. Since, with the present system, a finite time is required to detect a bubble pulse, the average void fraction $\phi$ is given by

$$
\phi=\alpha \frac{n t_{\text {store }}}{t_{\text {total }}},
$$

which makes the assumption that if the time taken to collect all the pulses $\left(t_{\text {total }}\right)$ is equal to the minimum possible $\left(n t_{\text {store }}\right)$, the average void fraction is the maximum possible ('Assumption 3'). The result is shown in figure 13.

The distribution of estimated void fraction is thus based on three assumptions. Of these, Assumptions 1 - that bubble distortions are self-similar - is questionable away from the bubble-formation zones; and Assumption 2 that bubble detections do not overlap - becomes contentious the longer the windowing period and the lower the trigger level. Nonetheless, the resulting distribution is generally consistent with both visual observations and data 
from an electrical void-fraction probe. The highest void fraction is in the region near the impeller tips. Considering both figures 12 and 13 , it may be concluded that the tank is performing reasonably well: the region of high void fraction generally contains smaller bubbles.

There is an interesting discrepancy between the acoustically estimated void fraction and the void fraction measured by an electrical probe (figure 14). The electric conductivity probe effectively averages the time its tip spends in air, and although this technique also has its problems (Dias, Franca, \& Rosa 1997), it is likely to be more reliable than the acoustic void fraction, given the assumptions above. The significant discrepancy is found at the edge where the tank floor and wall join. Here, the acoutic method reports a relatively high void fraction but the electrical probe reports a relatively low void fraction. One possible explanation is an acoustic amplification at walls and edges. It must be emphasized that the wavelength in water of sound at $1 \mathrm{kHz}$ is roughly $1.5 \mathrm{~m}$. Since this is much greater than the tank size, conventional theories of sound reflection do not apply and the process of amplification at an edge would be due to a near-field effect (Kinsler \& Frey 1950). Sound power falls off rapidly (as $\left.1 / r^{2}\right)$ and if a bubble were near a wall the pressure produced in its vicinity would be greater than if it were farther away. From (5) and (6) this would lead to an overestimate of void fraction.

\section{Conclusion}

An acoustic technique for bubble sizing can be applied at practical bubbling rates. However, nonlinear effects during the bubble rise alter the frequency. A spectral measure of bubble frequency can be related to the radius of the 
bubble just on formation, provided allowances are made for the frequency changes. The best match to the photographically-measured bubble radius is obtained when a 'frequency' based on the first period of acoustic oscillation is used. These results implied that the best technique was to capture individual bubble pulses and analyse them separately, rather than measuring overall spectra. Moreover, only the first few cycles of the pulses should be analysed.

Tests conducted on a sparged, stirred tank obtained a realistic distribution of mean bubble size with location in the tank. Further comparisons with an optical technique are recommended to cross-check this distribution. Reliable data are rapidly gathered near where bubbles are being formed and where the population density of bubbles is high, while reliable data rates are low in regions of low bubble population remote from the bubble formation. This is the reverse of optical methods, which fail in high bubble concentrations and excel in low concentrations.

It is also possible to obtain a rough distribution of average void fraction using the acoustic technique. However, three assumptions must be made to obtain a void-fraction distribution in a stirred tank environment. In particular, self-similar bubble distortions must be assumed, which is questionable in a complex bubbly flow.

Further research is also required to see how the passive acoustic technique can be translated into a practical measurement tool in a complex bubbly flow. In particular, the mechanism by which bubbles produce sound remote from their formation zone needs to be understood.

In a simpler bubbly flow where spatial distributions of the bubble size and void fraction are determined at their formation points, the technique may be immediately applicable. An example is a sparging plate or diffuser. 


\section{Acknowledgments}

We are grateful to Tracey Nicholls and Brook Dunstan for the photographic work and to numerous other colleagues at CSIRO for help with setting up the acoustic instruments and electronics. Knud Lunde (Norsk Hydro, Norway) was a great source of advice when setting up our first bubble experiment. 


\section{References}

[ Bhaga D; Weber ME (1981) Bubbles in viscous liquids: shapes, wakes and velocities. J Fluid Mech 105:, 61-85.

[] Boyd JWR; Varley J (1998) Sound measurement as a means of gasbubble sizing in aerated agitated tanks. Am Inst Chem Eng, 44:, 17311739.

[] Chhabra RP (1993) Bubbles, Drops, and Particles in non-Newtonian Flows. CRC Press, Boca Raton, Florida, USA.

[] Dias MI; Breit R; Riethmuller ML (1997) Non-intrusive measurement technique to analyze bubble formation. In: Giot, M; Mayinger F; Celata, GP (eds) Exptl Heat Transfer, Fluid Mechanics and Thermodynamics 1997, pp 949-956, Edizioni Ets, Pisa.

[ Dias SG; Franca FA; Rosa ES (1997) A generalized approach to estimate the size and velocity distributions of spherical bubbles using intrusive crossing probes. In: Giot, M; Mayinger F; Celata, GP (eds) Exptl Heat Transfer, Fluid Mechanics and Thermodynamics 1997, pp 957-970, Edizioni Ets, Pisa.

[) Hsi R; Tay M; Bukur D; Tatterson GB; Morrison G (1985) Sound spectra of gas dispersion in an agitated tank. Chem Eng J 31: 153-161.

[] Kinsler LE; Frey AR (1950) Fundamentals of acoustics Wiley, New York.

[] Knapp R; Hollander A (1948) Laboratory investigations of the mechanism of cavitation. Trans Am Soc Mech Eng 70: 419-435.

[] Lauterborn W; Hentschel W (1985) Cavitation bubble dynamics studied by high-speed photography and holography. Ultrasonics 23: 260-268.

[] Leighton TG; Walton AJ (1987) An experimental study of the sound emitted by gas bubbles in a liquid. Eur J Phys. 8: 98-104.

[) Leighton TG (1994) The acoustic bubble. Academic Press, London.

[] Longuet-Higgins MS (1989) Monopole emission of sound by asymmetric bubble oscillations. Part 1. Normal modes. J Fluid Mech 201: 525-541. 
[] Longuet-Higgins MS; Kerman BR; Lunde K (1991) The release of air bubbles from an underwater nozale. J Fluid Mech. 230: 365-390.

[] Manasseh $\mathbf{R}$ (1996) Bubble-pairing phenomena in sparging from verticalaxis nozzles. Proceedings, 24th Australian \& NZ Chem Eng Conference, Sydney, 30 Sep. - 2 Oct. Vol. 5, pp 27-32.

[] Manasseh R (1997) Acoustic sizing of bubbles at moderate to high bubbling rates. In: Giot, M; Mayinger F; Celata, GP (eds) Exptl Heat Transfer, Fluid Mechanics and Thermodynamics 1997, pp 943-947, Edizioni Ets, Pisa.

U Manasseh R; Yoshida S; Rudman M (1998) Bubble formation processes and bubble acoustic signals Proceedings, Third International Conference on Multiphase Flow, Lyon, France, 8-12 June.

(] Minnaert $M$ (1933) On musical air bubbles and the sound of running water. Phil Mag 16: 235-248.

[] Pandit AB; Varley J; Thorpe RB; Davidson JF (1992) Measurement of bubble size distribution: an acoustic technique. Chem Eng Sci 47: 1079-1089.

[1 Phelps AD; Leighton TG (1998) Oceanic bubble population measurements using a buoy--deployed combination frequency technique. IEEE J Oceanic Eng 23: 400-410.

[] Smith JM; Warmoeskerken MMCG (1985) The dispersion of gases in liquids with turbines. Proceedings, Fifth European Conference on Mixing, British Hydraulics Research Association pp 115-126.

Strasberg M (1953) The pulsation frequency of nonspherical gas bubbles in liquid. J Acoustical Soc America 25: 536-537.

[] Strasberg M (1956) Gas bubbles as sources of sound in liquids. J Acoustical Soc America 28: 20-26.

[] Tassin AL; Nikitopoulos DE (1995) Non-intrusive measurements of bubble size and velocity. Experiments in Fluids 19: 121-132. 
[] Zhu Y; Bandopadhayay PC; Wu J; Shepherd IC (1999) On the bubble size distribution in a stirred vessel with gas sparging. Proceedings, 27th Australasian Chemical Engineering Conference, Newcastle, Australia, 26-29 September, pp 1059-1064. 


\section{List of Figures}

1 Schematic of equipment set-up for continuous sparging tests. . 25

2 Acoustic pulse from the formation of a single bubble . . . . 26

3 Spectrum from the formation of single bubbles . . . . . . . 27

4 Bubble formation sequence . . . . . . . . . . . . 28

5 Bubble radius from spectral-peak frequency $R_{0 s p} . \ldots \ldots 29$

6 Bubble radius from reciprocal of first period $R_{0 f p} \ldots \ldots 30$

7 Acoustic versus digitized optical radii. . . . . . . . . 31

8 Airflow rate reconstructed. . . . . . . . . . . . . 32

9 Continuous spectrum from a stirred, sparged tank. . . . . . . 33

10 Windowed spectrum from a stirred, sparged tank. . . . . . . 34

11 Distribution of average bubble size, FFT method. . . . . . . . 35

12 Distribution of average bubble size, 1st-period method. . . . . 36

13 Acoustically estimated void fraction, $\phi$ (percent). . . . . . . 37

14 Void-fraction distribution measured by conductivity probe. . . 38 


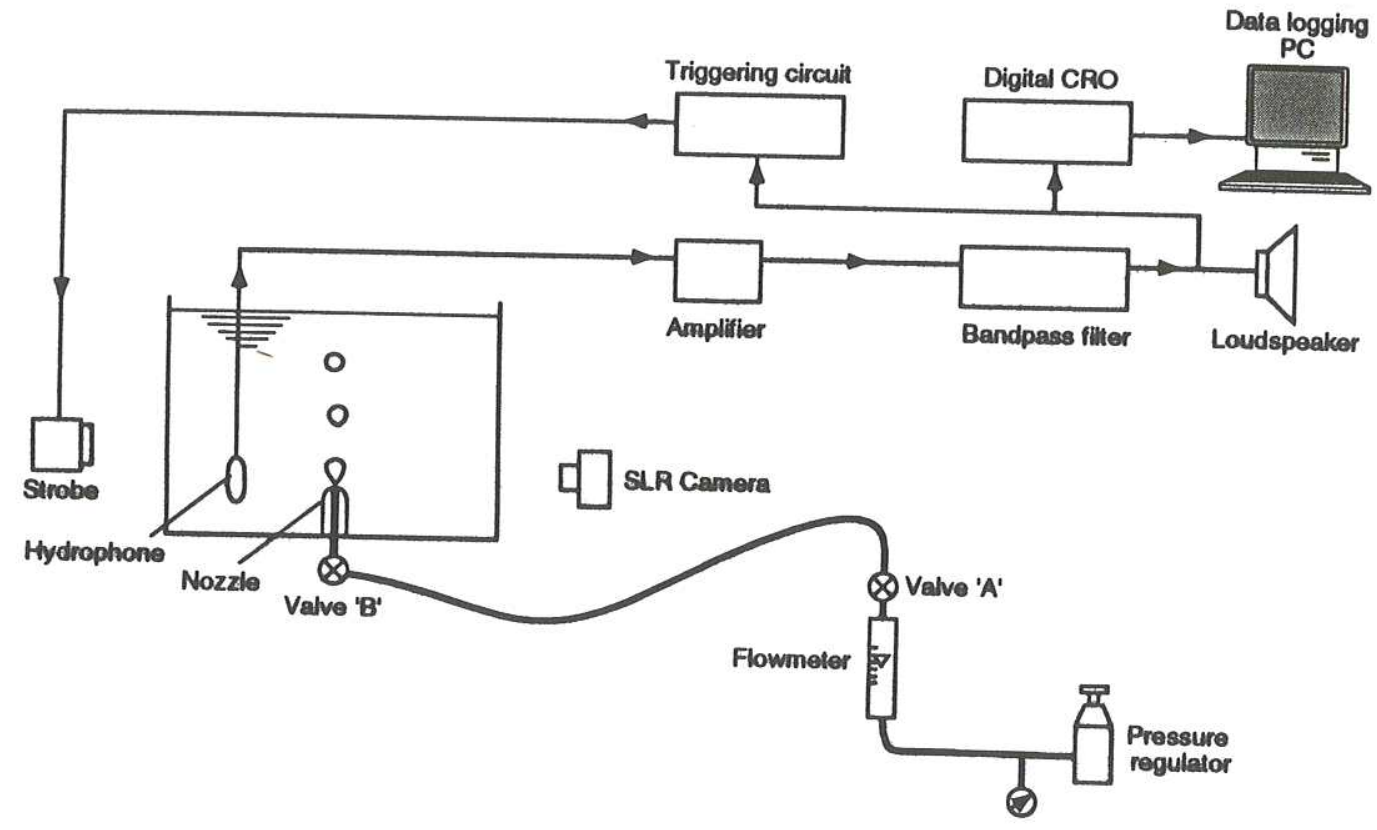

Figure 1: Schematic of equipment set-up for continuous sparging tests. 


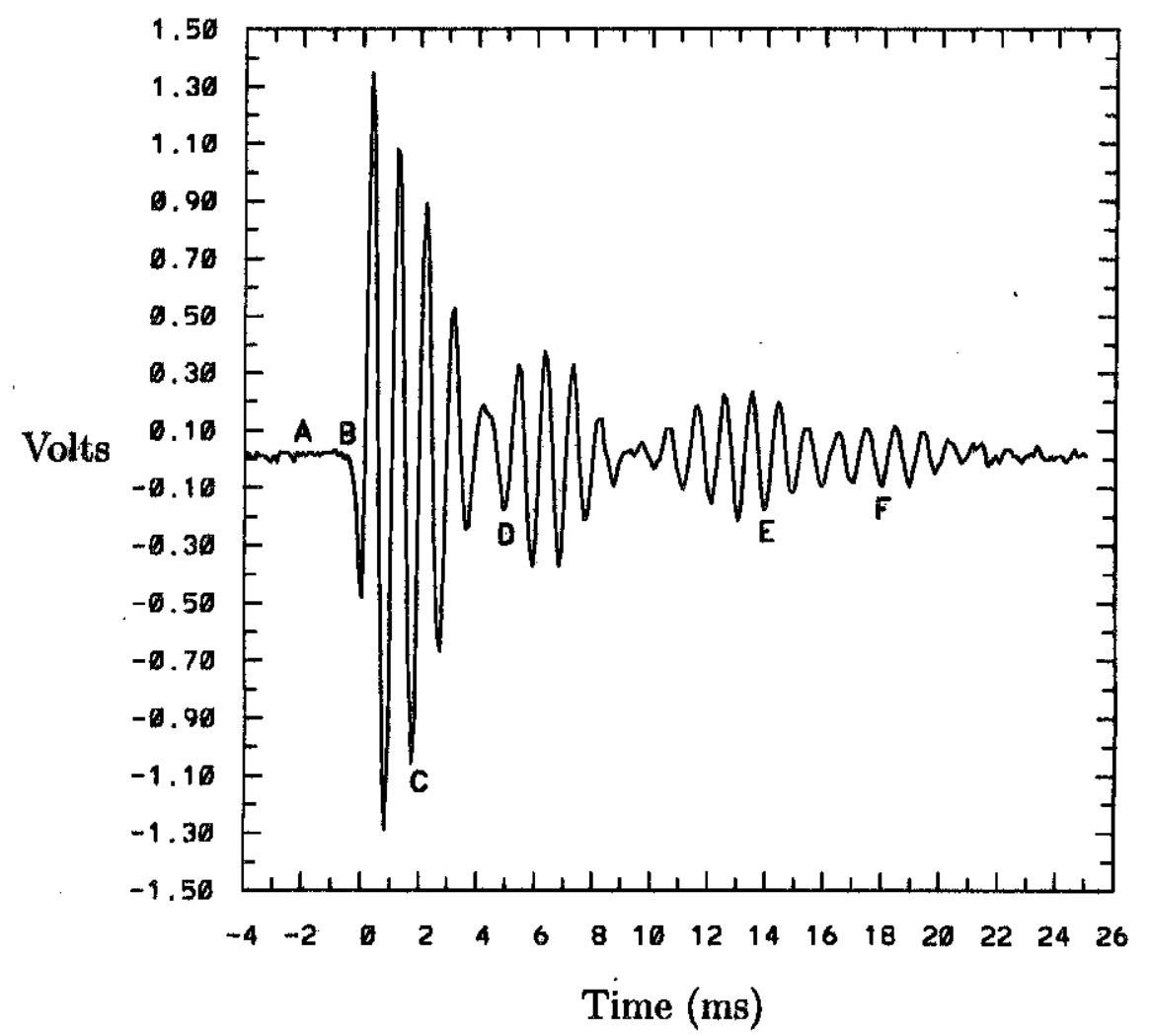

Figure 2: Acoustic pulse from the formation of a single bubble Bubble formed from a $4 \mathrm{~mm}$ internal-diameter nozzle submerged in water. The labels $\mathrm{A}-\mathrm{F}$ are centred at the times corresponding to the photographs in figure 4(a)$(f)$. 


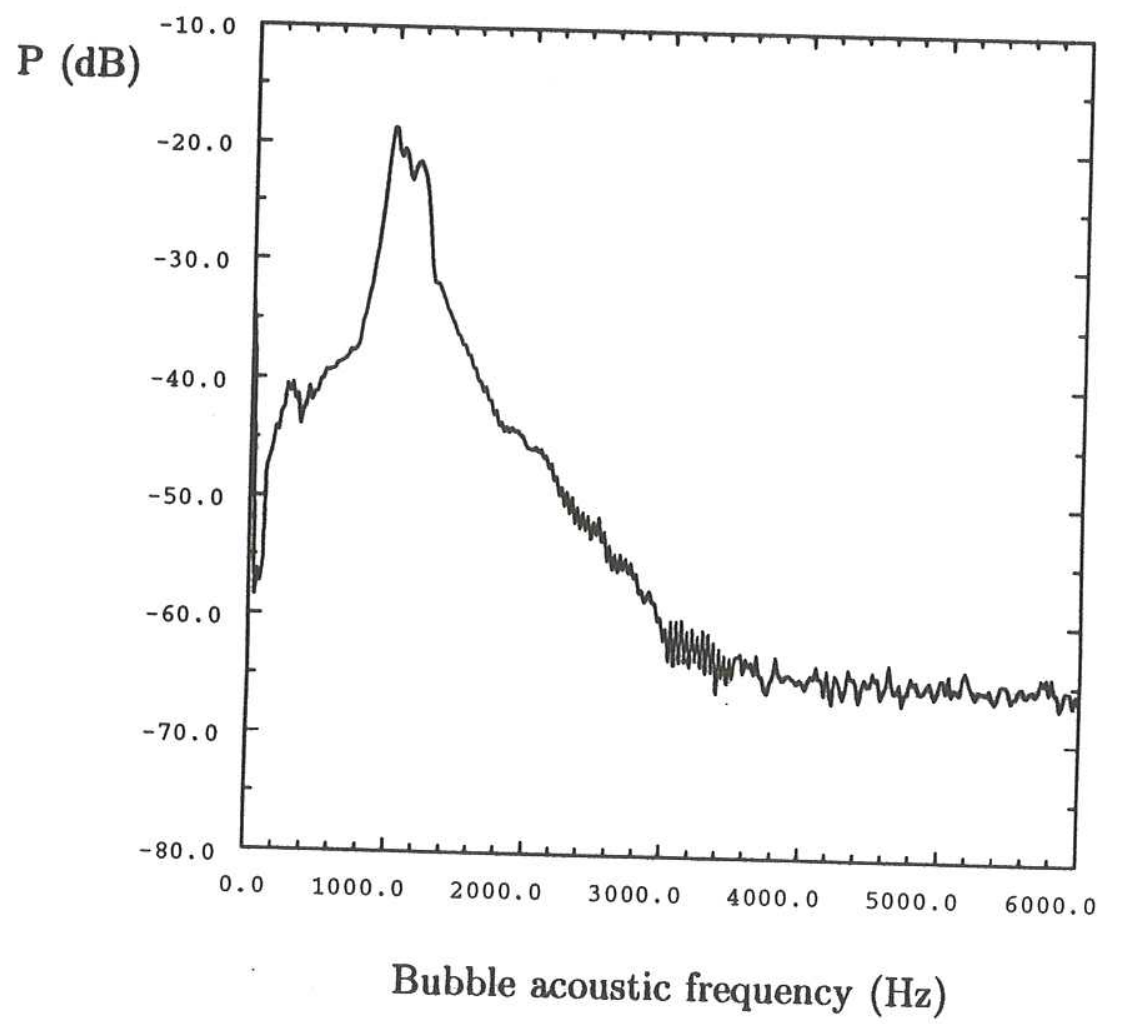

Figure 3: Spectrum from the formation of single bubbles Bubbles formed from a $4 \mathrm{~mm}$ internal-diameter nozzle submerged in water. Aver-
age of 30 ensembles. 

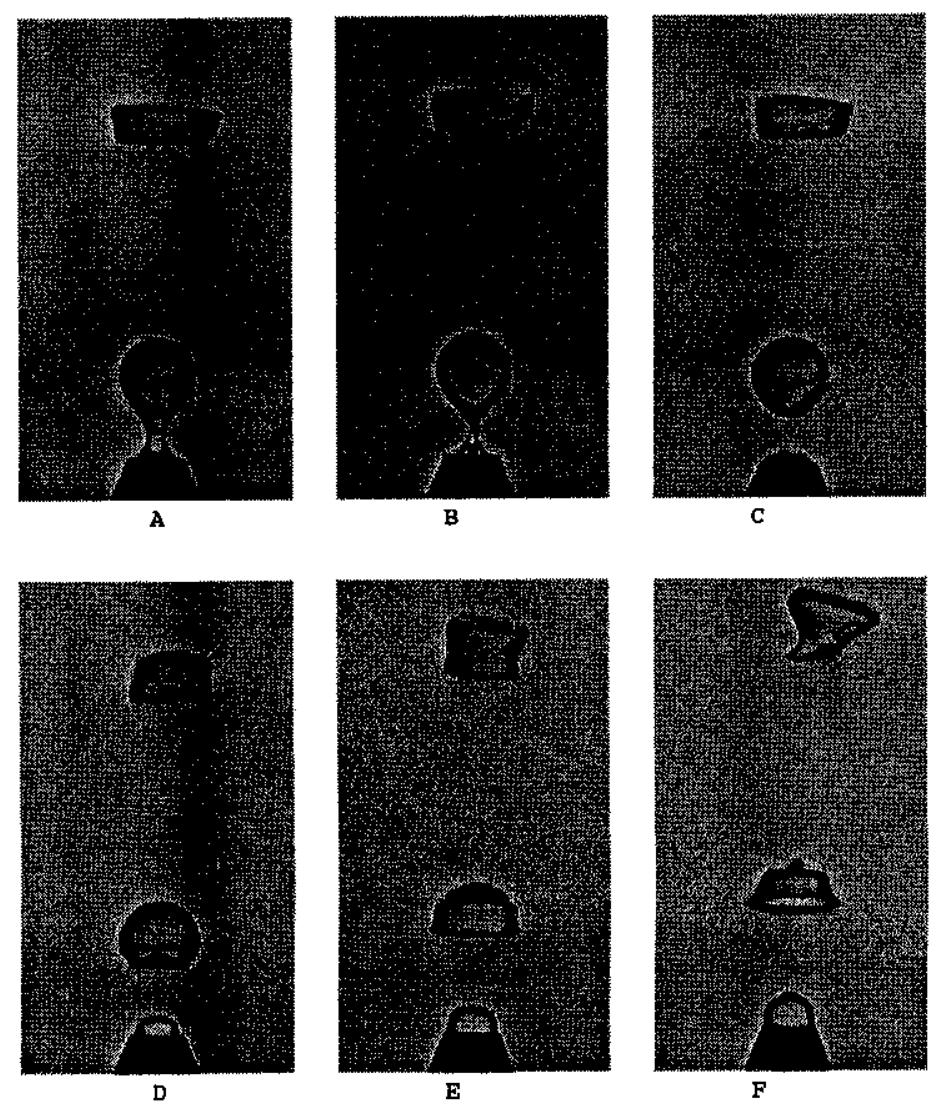

Figure 4: Bubble formation sequence

Bubble formed from a $4 \mathrm{~mm}$ internal-diameter nozzle submerged in water. Breaking of the neck occurs at $t=0$; times measured to $\pm 0.2 \mathrm{~ms}$. (a): $-2.0 \mathrm{~ms}$; (b): $-0.5 \mathrm{~ms}$; (c): $2.0 \mathrm{~ms}$; (d): $5.0 \mathrm{~ms}$; (e): $14.0 \mathrm{~ms}$; (f): $18.0 \mathrm{~ms}$. The sequence is produced by the acoustic triggering technique; hence the images are not of the same bubble. Bubbling is completely repeatable at this airfow rate. 


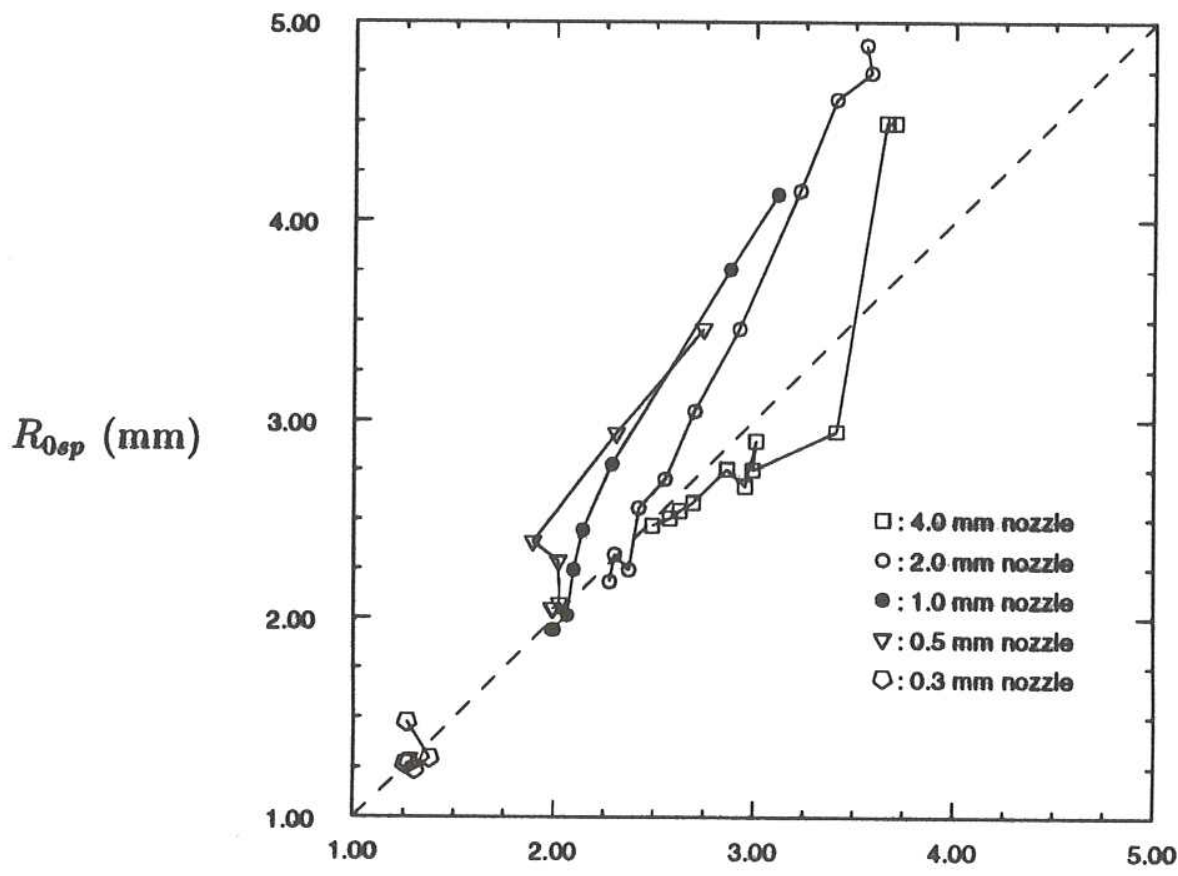

$R_{p}(\mathrm{~mm})$

Figure 5: Bubble radius from spectral-peak frequency $R_{0 s p}$.

Radii plotted versus photographically measured radius $R_{p}$. Spectra were averaged over 30 ensembles; photographic radii are half the bubble-image's minor axis. Errors in photographic measurements range from $1 \%$ for larger bubbles to $4 \%$ for smaller bubbles. Five different nozzle sizes are used, denoted by different symbols. 


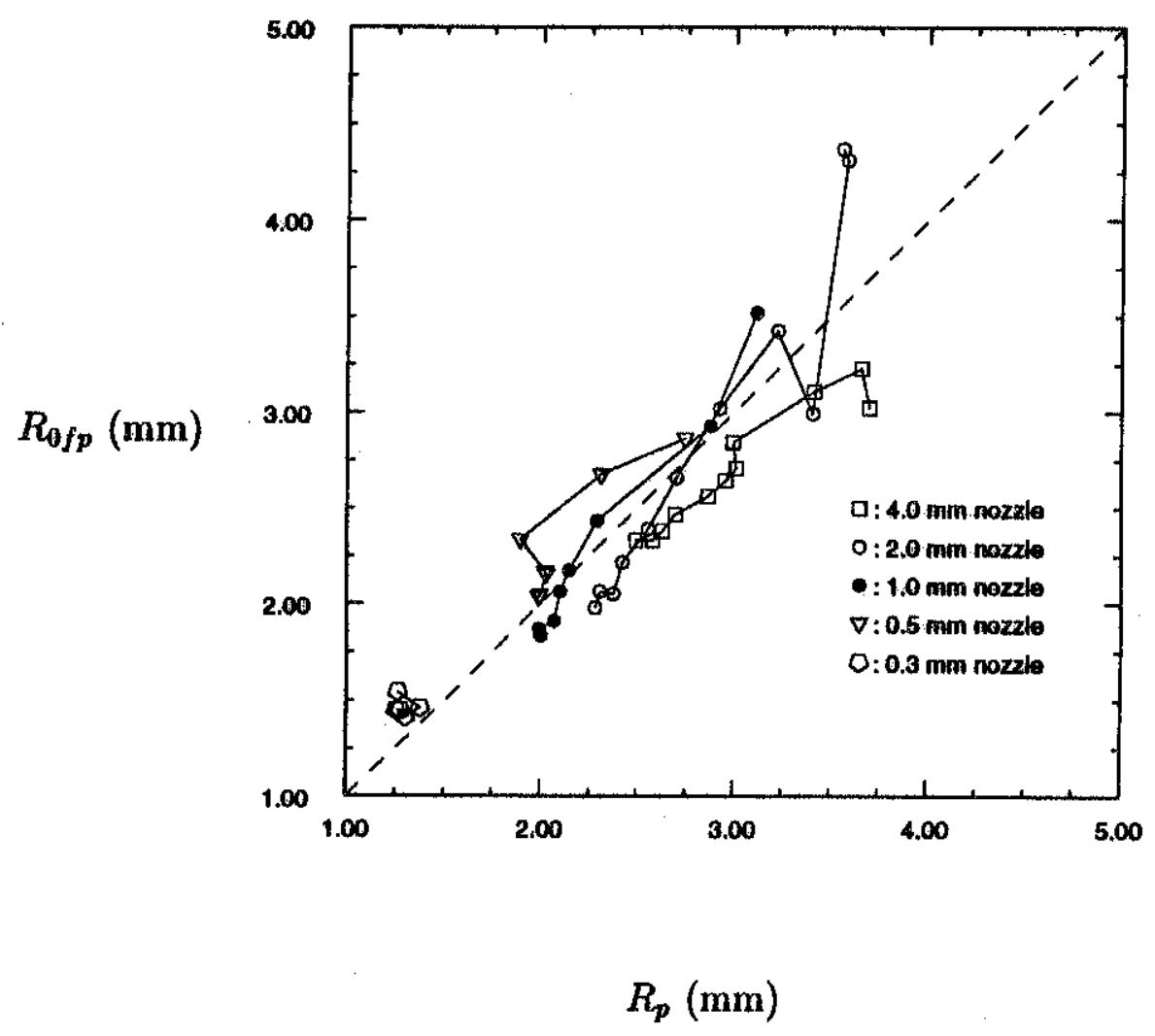

Figure 6: Bubble radius from reciprocal of first period $R_{0 f p}$.

Radii plotted versus photographically measured radius $R_{p}$. Photographic data as in figure 5. 


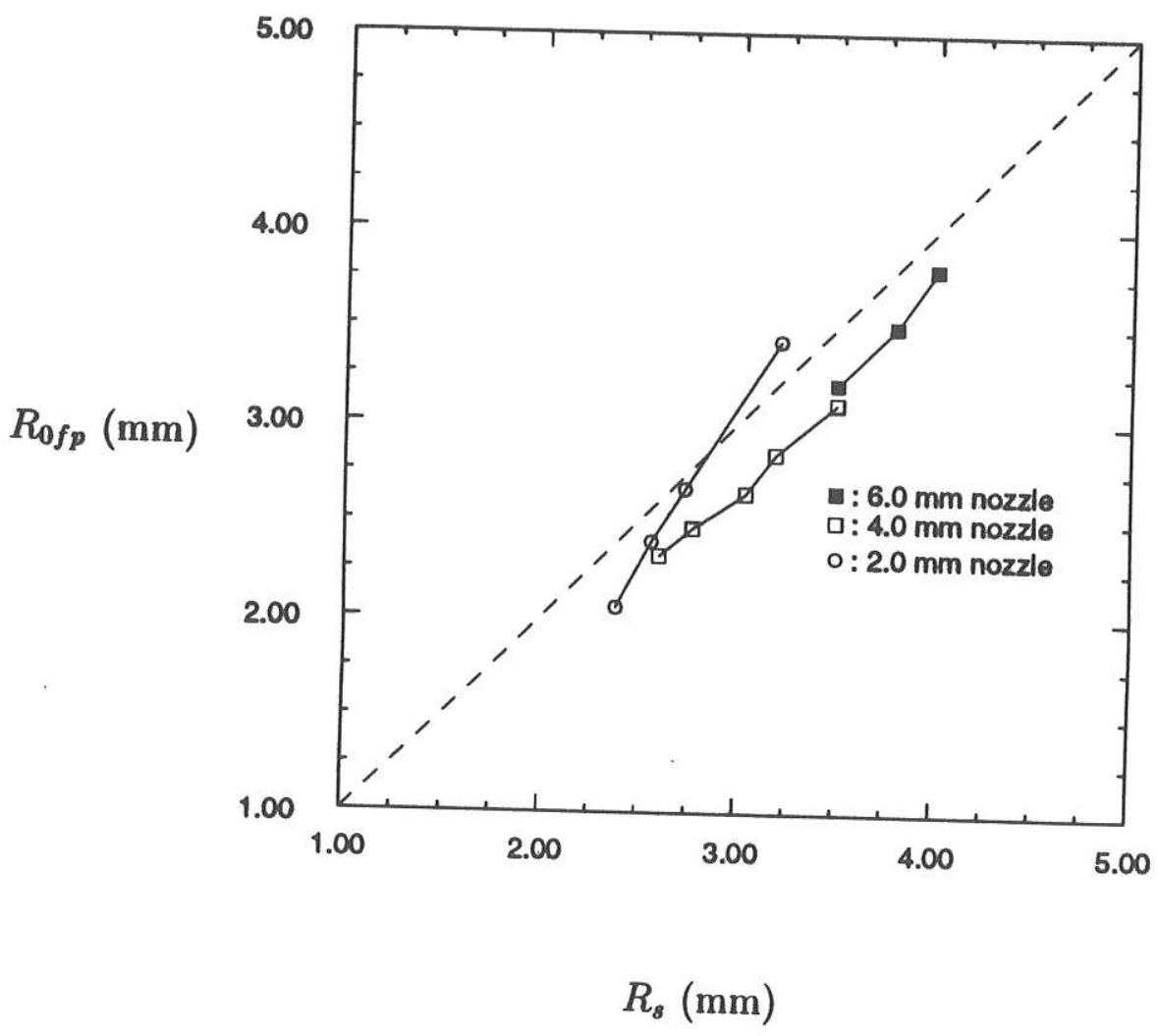

Figure 7: Acoustic versus digitized optical radii. Radii plotted versus software-estimated radius $\boldsymbol{R}_{\boldsymbol{s}}$. 


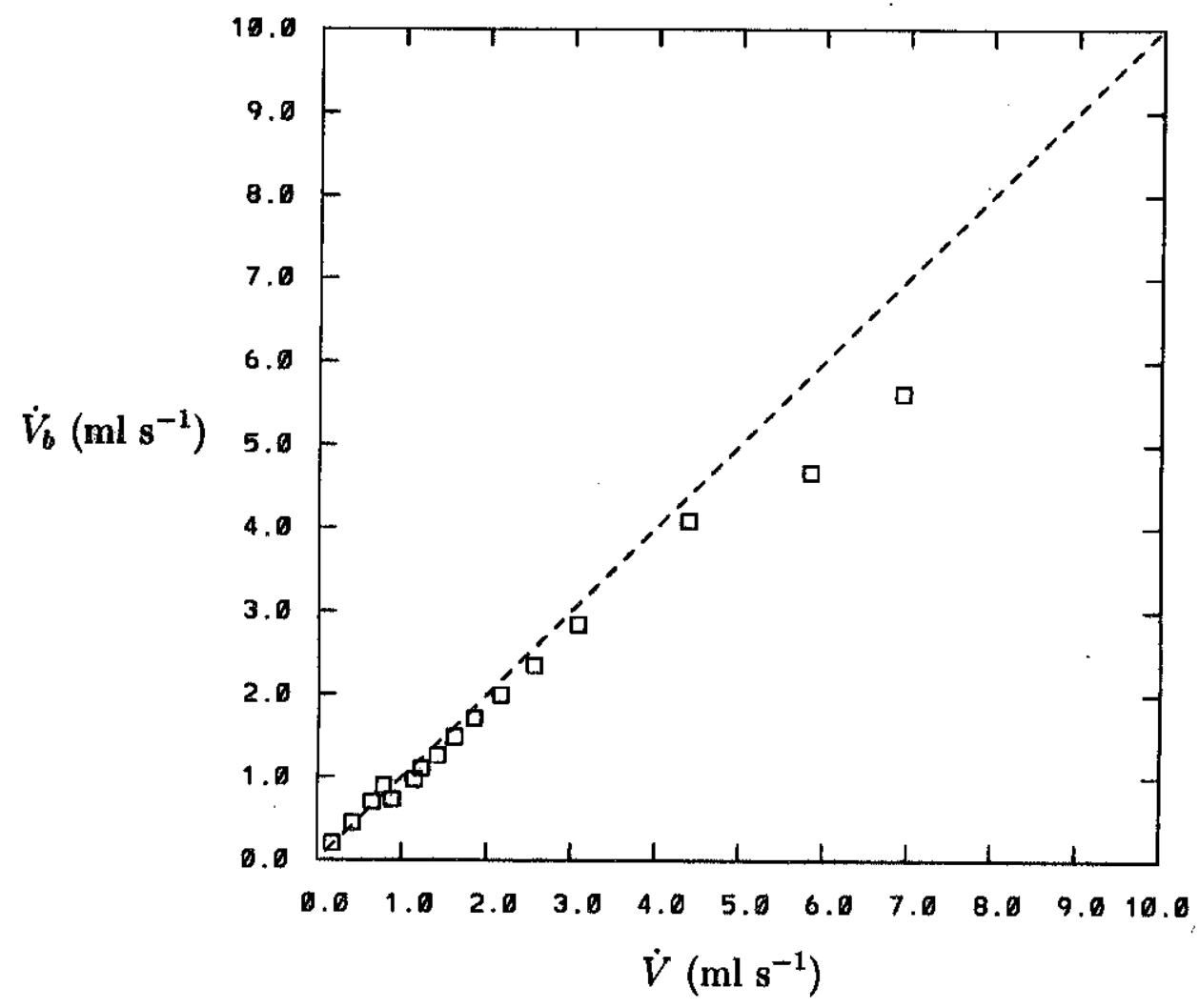

Figure 8: Airflow rate reconstructed.

Flow through nozzle reconstructed from measurements of bubble frequency and bubbling rate, $\dot{V}_{b}$, versus calibrated air flow rate, $\dot{V}$, for a $4 \mathrm{~mm}$ internal diameter nozzle submerged in water. 


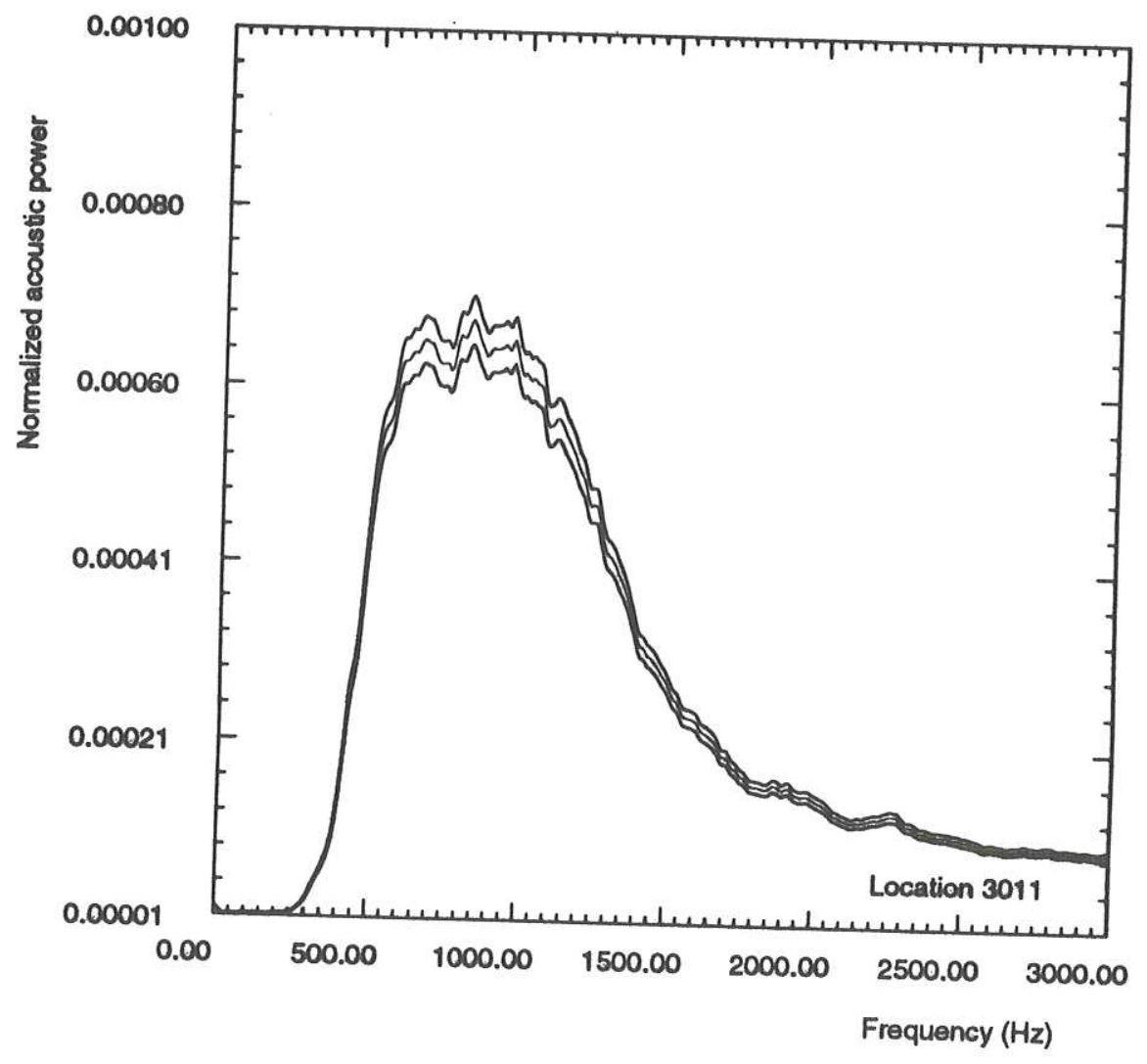

Figure 9: Continuous spectrum from a stirred, sparged tank.

Central curve is the mean of 2224 spectra; outlying curves represent $95 \%$ confidence limits. 


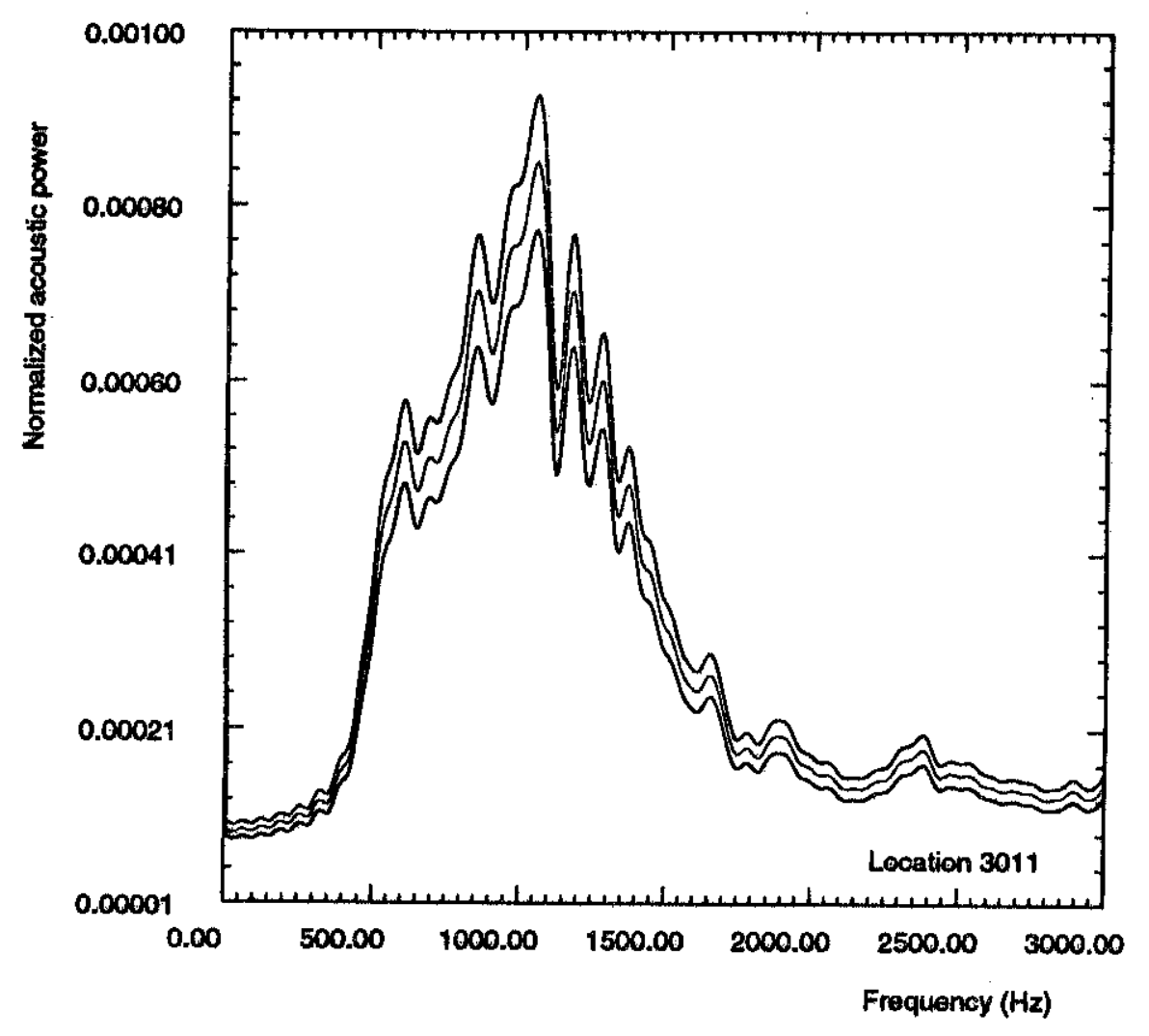

Figure 10: Windowed spectrum from a stirred, sparged tank. Central curve is the mean of 100 spectra; outlying curves represent $95 \%$ confidence limits. 


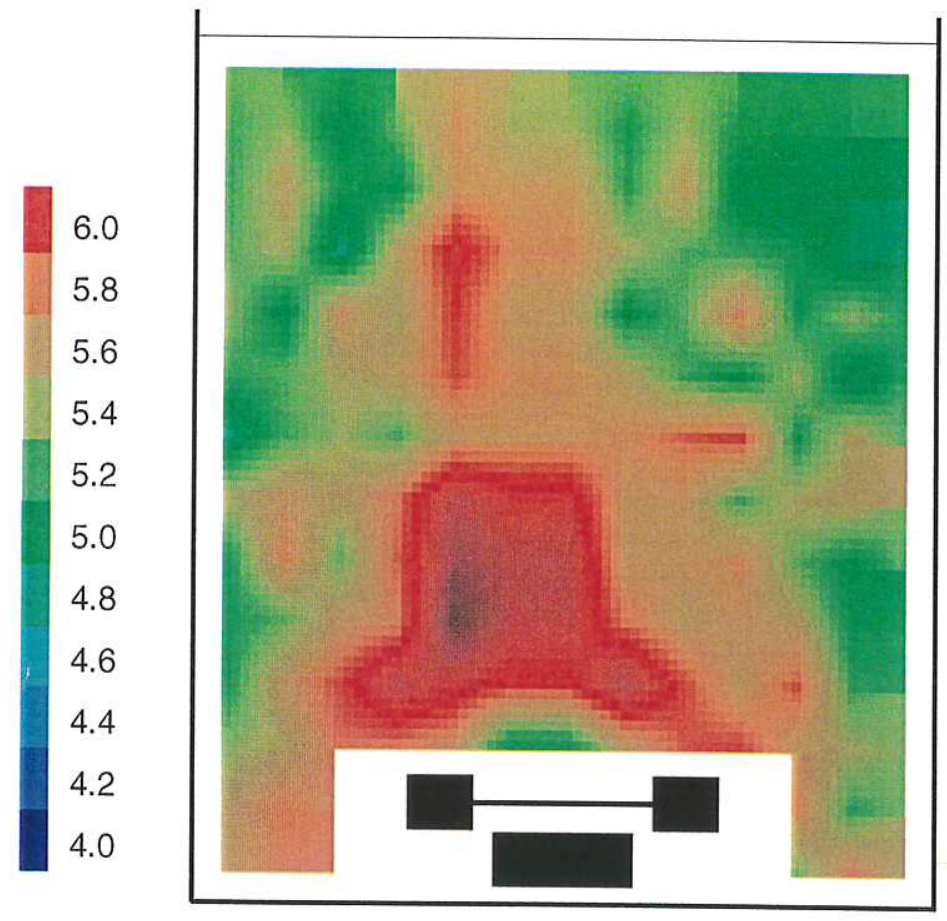

Figure 11: Distribution of average bubble size, FFT method. Bubble diameters in mm calculated from 4096-point FFTs over $125 \mathrm{~ms}$. 



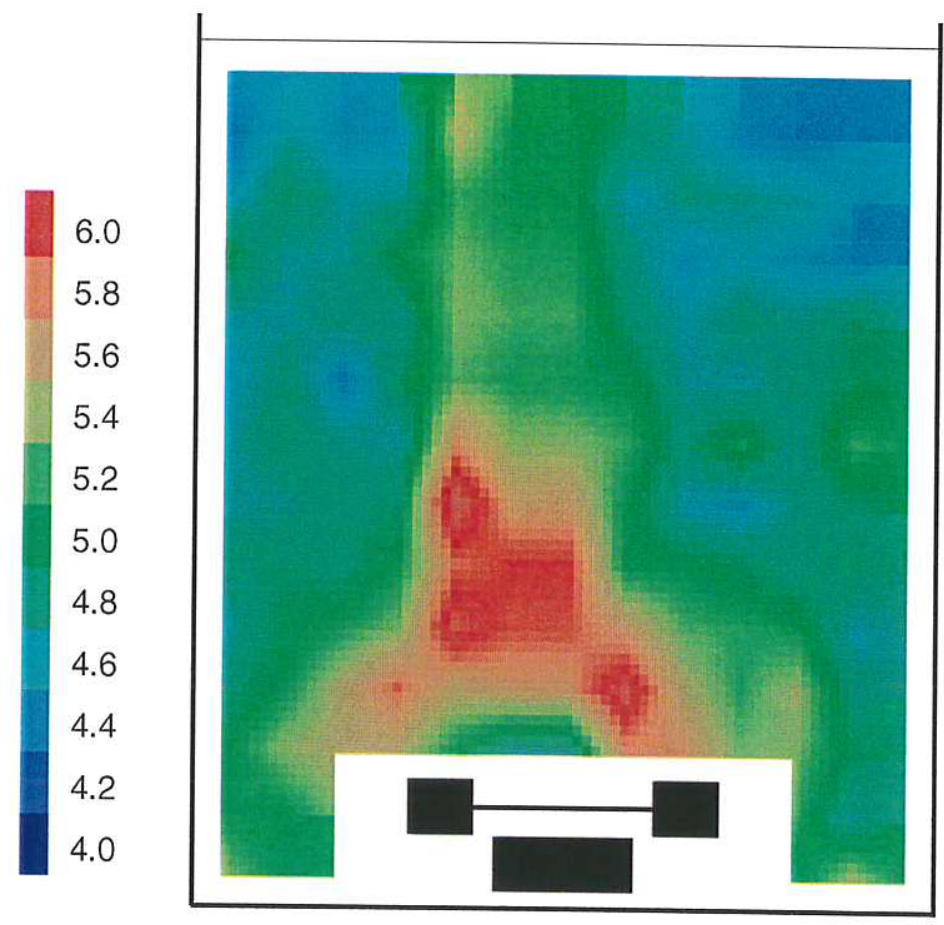

Figure 12: Distribution of average bubble size, 1st-period method. Bubble diameters in $\mathrm{mm}$ calculated from the 1st period only. 


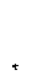




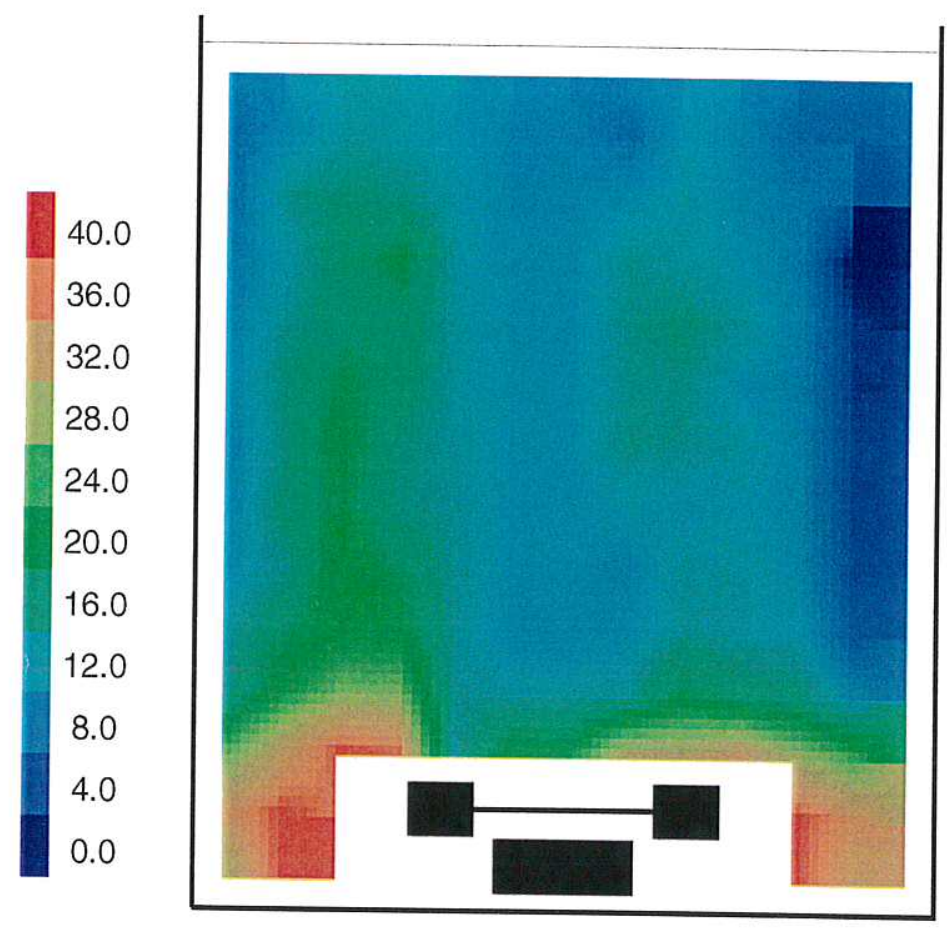

Figure 13: Acoustically estimated void fraction, $\phi$ (percent). 


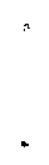




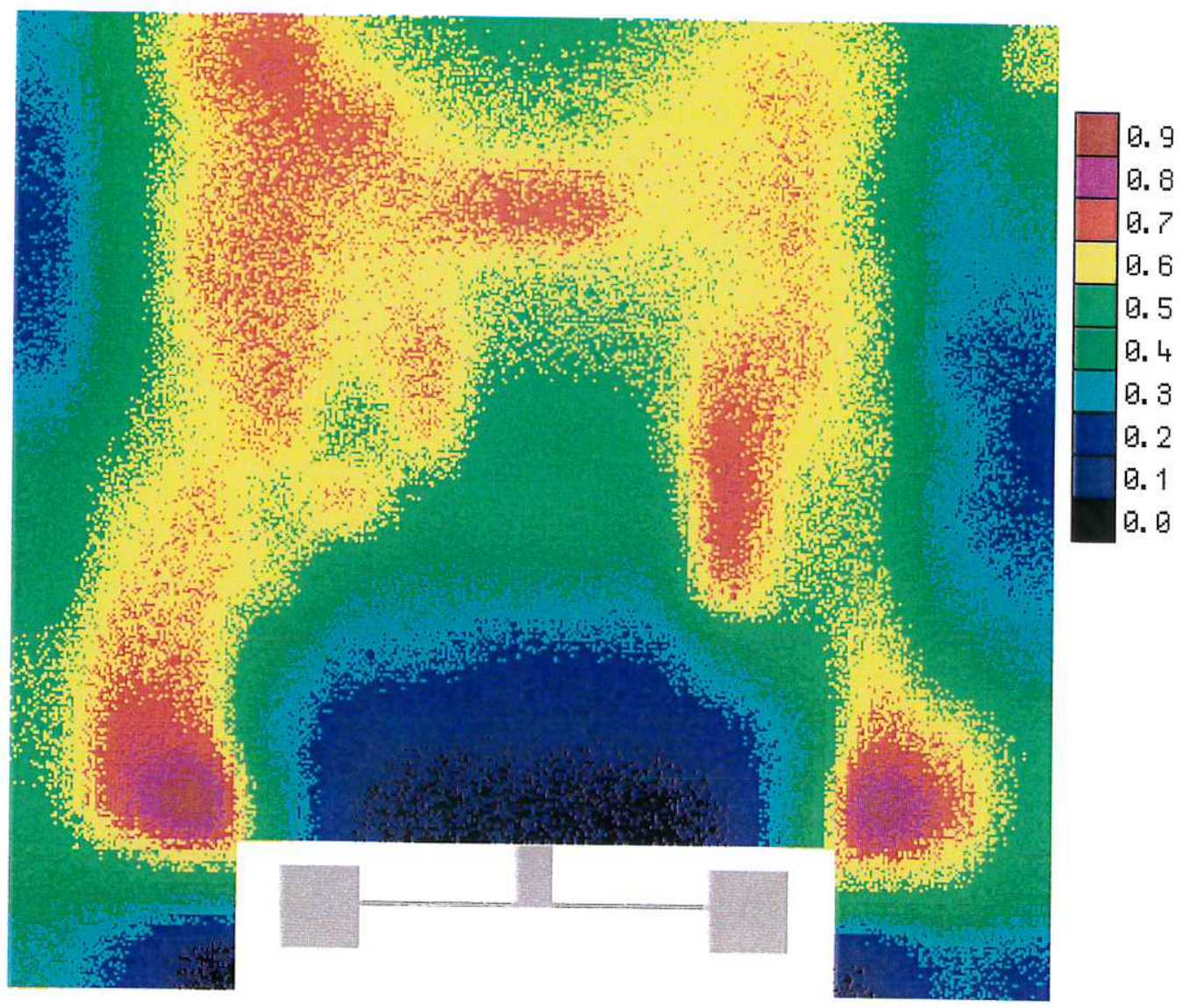

Figure 14: Void-fraction distribution measured by conductivity probe. A value of 1.0 represents the maximum recorded, in this case $15 \%$. 


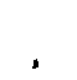

. 